\title{
REGULARITIES OF REFORMING PUBLIC ADMINISTRATION MECHANISMS OF THE HEALTH CARE SYSTEM IN UKRAINE IN THE CONTEXT OF THE EUROPEAN DIMENSION
}

\author{
Maxsym Dolgich ${ }^{1}$ \\ ${ }^{l}$ postgraduate student, Department of Public Management and Administration, Interregional Academy \\ of personnel management, max.dolgih1 @ gmail.com, ORCID https://orcid.org/0000-0001-7333-4595
}

\begin{abstract}
The article presents systematic approaches to the regularities of reforming the public administration mechanisms of the health care system in Ukraine, taking into account the international aspect. It is substantiated that the principles that are important for the formation of the national system of public administration mechanisms of the health care system in Ukraine are the following: a well-established process of interaction between the state, the private sector and the citizens themselves; balanced distribution of health care responsibilities between state and local governments; organizing a health care system based on high competition and consumer orientation; availability of medical services, convenience in obtaining them through efficient use of available resources; creation and development of the health insurance system.
\end{abstract}

Keywords: health care system, health care system reformation, health care system personnel, public administration of the health care system.

JEL Classification: H10, I10, I18

Formulas: 0; fig.: 0; tabl.: 0; bibl.: 18.

Introduction. Today, as obvious as ever, there is a need for medical reform that is not only "ripe" but also, to some extent, "overripe." The realization of human rights in quality health services should determine the direction of public policy in Ukraine to reform the current health care system and to create an effective national model for managing its public administration mechanisms. This task will be facilitated by an analysis of the experience of organizing the health care industry in European countries whose health care systems have been recognized as successful.

The governments of many countries in the European region within the World Health Organization are constantly reviewing their health care systems, assessing the appropriateness of their approaches to financing the organization processes and delivery of health care services. In the meantime, in our opinion, the modernization of the health care system, in its content, should be carried out both in regulatory, economic and organizational directions. After all, the effectiveness of measures to transform the health care system is evaluated not only in terms of short-term savings from the state budget for the development of the medical industry, but also in terms of the ability, in the long term, to improve the health of the entire population. These regulatory indicators are equally important for the health care system reformation in Ukraine and in foreign countries.

Literature review. Political scientists, lawyers, economists, financiers, specialists in public administration analyze problems of reforming and developing the health care system, among them: solving problems of reforming the health care system, mechanisms of public administration reforming the 
medical sphere are M. Bilynska, O. Vashev, Y. Zima, D. Karamyshev, O. Pavlenko, O. Prokopchuk, I. Rozhkov, V. Rudy, Y. Radysh and others.

Aims. The purpose of this article is to determine the regularities of the reform of the mechanisms of public management of the health care system in Ukraine in the context of the European Union.

Methods. The system method, induction and deduction method, generalization method and comparative analysis are used in the article.

Results. The processes of transformational change in national health care systems in European countries are, for the most part, related to the organizational, regulatory and economic aspects of health care. The reassessment of existing public administration mechanisms of the health care system should primarily address the issues of financing, economic regulation, and regulatory support for treatment and quality control of health care services provided. All this is done to improve the effectiveness and efficiency of the fight for health care, while respecting the ethical imperatives of medical development in general. Different countries do this differently, taking into account their demographic, socio-economic, national, medical, organizational, territorial and other developmental characteristics.

Discussion. Studying the main aspects of the European dimension of reforming the public administration mechanisms of the health care system allows us not only to analyze individual modern models of medical systems, but also to substantiate their effectiveness and topicality of implementation in the Ukrainian national health care system [1, p. 91].

Analyzed world experience has shown that in recent decades, one can observe the active development of public-private partnerships, reflecting the processes of expanding and building a new form of state-business relations in order to provide a competitive environment for social and economic progress. World experience has shown that the most common forms of involvement of private entities in partnerships in health care include [16]:

- contracts provided by the state to private companies for the purpose of performing works and services, as well as supplying products for the fulfillment of state needs, etc. The most common contractual form of public-private partnership used in large-scale projects in international practice is the concession agreement;

- system of lease relations, which arises when the state leases its property to private entities: buildings, production equipment, etc., and rent is paid for the use of state property by private companies;

- creation of public-private companies. Private sector involvement in the realization of a state-owned enterprise's capital may include the corporatization and formation of joint ventures. The degree of freedom of the private sector, however, in making administrative and economic decisions is determined by the size of its share in the authorized capital. The smaller the share of private investment compared to public investment, the less the private sector has the capacity to make decisions that the government will not interfere with. 
Against this background, it should be noted that the absolute reproduction of models borrowed from world experience regarding the ways of implementing the "design" of public-private partnerships in the field of health care of Ukraine may not produce the expected result. In addition, the development of the health care system is fraught with high social and significant commercial and political risks. The rapid, unbalanced implementation of a public-private partnership project in this area in Ukraine today can lead to economic losses for the government and the private sector, as well as to an increase in social losses for the population as a whole [16, p. 147].

Therefore, in our opinion, it is necessary to develop and implement instruments of institutional, regulatory and methodological support for the potential implementation of public-private partnership projects in the field of health care in our country.

Let us consider in more detail the experience of which European countries can be used by the Government of Ukraine in reforming the existing public administration mechanisms of the health care system.

The health care system of the United States of America is of value to both employers and citizens, making it difficult to provide health care to the entire population. But, at the same time, this system is a world leader in many positions: quality of medical services, qualification of medical personnel, treatment of specific diseases, basic researches in the field of medicine, use of the latest technologies and more. The United States of America has established a health care system based on highly competitive and consumer-oriented approaches that promotes high levels of health care delivery and enhances the professionalism of physicians. This, in turn, can be used to create an effective health care system in Ukraine [9].

It should also be noted that the experience of the United States of America can be applied in Ukraine to improve legislation on:

- financing programs for providing medical assistance to low-income individuals;

- expanding the health care network in the regions;

- development of an optimal mechanism for stimulating the work of health workers;

- covering the costs of implementation of state programs created for the prevention of diseases, etc.

The aforementioned changes can be one of the stages of gradual implementation of the mixed model of financing of the health care system in Ukraine and further coverage of health insurance of the whole working-age population.

Also, national disease prevention programs should be optimized in Ukraine, which will include optimization of general hygiene education, compulsory medical examinations, and monitoring of certain types of diseases, vaccination consequences, and the like. This should reduce the incidence rate of the population and health care costs without compromising the quality of health 
care overall. An example of the positive implementation of disease prevention programs is Japan, which has become one of the few countries with a high life expectancy (86 years for women and 79 years for men) [6].

In Ukraine, as in the UK, the state creates the conditions for effective and affordable health care for all citizens. Medical care is provided free of charge in state and municipal health care facilities; the existing network of such institutions cannot be reduced. The state promotes the development of health care facilities of all forms of ownership [2]. In addition, the Law of Ukraine "On State Financial Guarantees for Medical Care of the Population" [4] provides for citizens to obtain the necessary medical services and medicines at the expense of the State Budget of Ukraine aimed at the implementation of the program of medical guarantees from medical professionals. However, according to Part 3 of Art. 4 of this Law, medical services and medicines not included in the program of medical guarantees are not payable at the expense of the State Budget of Ukraine provided for the implementation of the program of medical guarantees.

According to Art. 10 of the Law of Ukraine "On State Financial Guarantees of Public Health Care [4], uniform rates for payment of medical services, medicines and medical products provided to patients under the program of medical guarantees are set for the whole territory of Ukraine. Payment at a uniform rate is guaranteed to all health care providers in accordance with health care agreements [6].

However, this law establishes partial payment for medical services. Therefore, in addition to these tariffs, you should set maximum prices for medical services provided by private health care facilities. Such tariffs, for example, in Japan are regulated at the state level, so patients do not feel the difference when accessing a public or private health care facility [6].

Crucial in the experience of European countries, in particular in the UK, are the public administration mechanisms to protect human rights, especially vulnerable sections of the population: minors, disabled people, retirees and others. On this basis, it is advisable to develop and implement state medical programs to support retirees in order to increase life expectancy in Ukraine, as well as to support the activity of the Ukrainian population in the "third age" [6].

Health care reformation in Ukraine is practically impossible without prioritizing public administration of its system. Based on the experience of the British health care system, as well as, taking into account the experience and mistakes of other developed countries, the following priorities can be distinguished: introduction of a mechanism of payment for medical services on the principle of "money goes after the patient", availability of medicines and raising public awareness of government actions aimed at reforming public administration mechanisms of the health care system in Ukraine in the context of the European dimension.

The state, for its part, should change approaches to financing the health care system: not to focus, first of all, on the allocation of funds for the payment of the "walls" of health care facilities and public utilities, but on the provision of 
medical services that patients need. Usually, these are primary and emergency medical care. This should be the "engine" of change at the secondary and tertiary levels of health care delivery [7].

The strategy for "human-centered health care" is being implemented in the European region. The complex nature of care is provided through the existing wide range of treatment, rehabilitation and prevention services directly by primary care physicians or specially organized in other institutions. The essence of this strategy is ultimately reduced to such directions as [5, p. 82]:

- formation of the market of medical services and transfer to it of the basic regulatory functions with gradual departure of the state from administration processes of activity of health care facilities;

- strengthening of the regulatory functions of the state in the conditions of development of market public administration mechanisms of the health care system, which is especially important for limiting the negative influence of the market on the availability of medical care;

- formation of integrated structures that contribute to the economic growth of the medical industry and the like.

The strategy of "human-centered health care" is mainly realized in countries implementing market-oriented reforms of the social sphere as a whole, as is the case in modern Ukraine. In the context of such reforms, it is extremely important to strengthen the regulatory role of the state as the main guarantor of the accessibility and safety of medical care. Quality assurance remains a key challenge for health care providers and an indicator of their competitiveness.

The role of governing bodies in ensuring the quality of the health care system is to provide the conditions for the formation and rational use of appropriate resource potential (logistical, human, etc.), as well as to stimulate innovative models of quality management. The need to strengthen government regulation in the health care field has served as the basis for the implementation of the following specific strategies, including the formation of "regulated competition" between health care facilities, as well as between health care insurers.

For our country, the problem of integration of facilities with insurance organizations is not urgent due to the limited development of the insurance business and the actual absence of competition in the health care market [5, p. 82].

During 2012-2019, total health care expenditures in Ukraine accounted for $7.7 \%$ of GDP per year (approximately $4.1 \%$ of the state budget and about $3.6 \%$ of the private sector, mainly household and its expenditures components), which is, in fact, not very different from global and European trends in the financing of the medical industry. In the European region, overall health care spending is $8.9 \%$ and overall $-8.6 \%$ worldwide. However, due to low GDP, this per capita cost is only around $\$ 200$, well below the European Union average of $\$ 3,340$.

In order to address this issue, Ukraine is introducing a modern model of solidarity health insurance, taking into account the best current practices and 
experience of transforming health care systems in the world, especially in the countries of Central and Eastern Europe. The main source of financing for the renewed health care system is the State Budget of Ukraine, mainly from national taxes. However, payments for the treatment of an individual are not related to the amount of the individual contribution amount of the person [10].

It should be noted that in recent years, there has been a gradual transition of the Ukrainian health care system to the insurance model of its formation. However, the number of diseases is increasing, the level and quality of medical services are not significantly improving, the financial status of medical personnel leaves much to be desired, which requires the health insurance system reformation in Ukraine, as well as the study of foreign experience on its implementation in our country [14].

We agree with V. Stetsenko's opinion that among the positive aspects of the organization of the compulsory health insurance system in Germany, which should be used in Ukraine in reforming the public administration mechanisms of the health care system are the following [13, p. 63]:

- payment for medical services provided by physicians is made on the basis of a point system of assessing the level of services provided by them, which eliminates the possibility of abuse by medical professionals;

- ability of a person whose income exceeds a fixed amount to leave the compulsory insurance system and move to the private insurance sector;

- employee's ability to provide health insurance to non-working family members;

- possibility of free choice of insurance company, physician, health care facility, etc.

The high level of development of compulsory social health insurance, with the exception of Germany, is typical for countries such as France, the Czech Republic, the Netherlands and some other countries where the share of the costs of this type of insurance, in the total amount of health care costs, is approximately $90 \%$. Unlike Germany, the insurer in France is the National Insurance Organization, so compulsory health insurance takes a centralized form. All major French health insurance programs are implemented in practice by the National Health Insurance Fund and relevant local structures.

Thus, summarizing the interim results of the study of the European experience in reforming public administration mechanisms of the health care system, it should be noted that in all countries different forms and types of health insurance are applied, both voluntary and compulsory, and only such economically developed countries, like the UK, Sweden, Canada, can afford to have a public health care financing system, the organization of which is covered in more detail in the previous paragraph, but even in these economically advanced countries, there are health insurance systems. [11]

In Ukraine, the insurance market is not as developed as in other European countries, because in the last few years our country's economy is in a very 
fragile and uncertain state. That is why Ukrainians try to raise more money instead of making long-term deposits, even if it concerns their health.

But despite this, the insurance medicine market in Ukraine exists and tries to actively develop even in such difficult conditions. The most common is the so-called insurance of a person, which the client concludes personally with the insurance company. Sometimes health insurance is part of the social package of large companies, but it has a relatively small market share.

After all, even in our country, health insurance is a great benefit for clients of insurance companies. When an insured event occurs, it allows a person not to worry about the cost of medication and the examination they need. In addition, the client knows exactly the amount that he can expect to pay for certain health care services. If a health care facility violates health care standards, the insurance company may refuse to pay them in full or in part.

In our opinion, there are two major disadvantages of health insurance. First, if in a year (or some other time specified in the insurance policy) the insured event does not happen to you or you do not need medical help, then no one will refund the money.

Secondly, you need to clearly understand what insurance payments will be made according to the terms of your policy. If you become ill with something that is not specified in your insurance contract, the company will not compensate for the payment for medical services.. For example, often health insurance does not include a package of dental services provision, or they are very limited [18].

Therefore, based on the above review, we can only conclude that there is no alternative to health insurance. Health insurance is the only way out of the health care system of Ukraine from deep economic and social crises [11].

World experience shows that the best option for the practical implementation of the principles of medico-economic feasibility of functioning of the health care system is the Institute of Family Physician - General Practitioner. Its task is to formulate the most optimal way of examining and treating its patients and thus to manage the entire scope and process of care assistance. The benefits of the Institute of Family Physician are also that it enables the existing health care fund to clearly differentiate the functions and financial flows of primary care, secondary outpatient care and hospital care, ie to achieve the managed care effect. In addition, this new concept involves the use of modern information and management technologies [3].

As for Ukraine, it is known that family medicine has existed for over 15 years, however, it has not been fully realized due to a number of factors such as $[17$, p. 6]:

- inconsistency of state policy with European standards of development;

- imperfection of the legislative base, non-systematic approach to its organization;

- insufficient training of medical personnel; 
- uncertainty about the amount of medical care and the level of development of the route or the procedure of referral of the patient to the family physician, etc.

In real-life examples, we provide feedback on the experience of using Ukrainian health care services for patients living in the United States, Germany, Britain, and France.

All respondents noted a huge difference, compared to Ukraine, in the physician's attitude towards the patient as a client. However, it is part of an established culture of social communication in all spheres of public life in developed countries - in the group, in the service sector, in private communication. Therefore, in clinics, regardless of their ownership, the attitude is friendly, starting with the lowest level of staff and ending with the highest management. People have long realized that they live in a shared space and there is no reason to create additional problems for themselves. Therefore, no illtreatment or rudeness. As a result, physicians are trusted because, as the legislation in the field of medicine is very advanced, there are authorized bodies that constantly monitor the level of service delivery, compliance with professional ethics, and corruption as such is absent at all. In addition, physicians adhere to clinical protocols when prescribing treatment, so the influence of pharmaceutical companies on decision-making by doctors in European Union countries is minimized, unlike in Ukraine. That is why the implementation of mandatory protocols in Ukraine is of great importance for eliminating the adverse effects of pharmaceutical agents on physicians.

In Ukraine, in addition to the general principles of compensation for harm caused by a physician, there is no specific medical legislation. The rudimentary remnant of the Soviet Union is a division in which one physician diagnoses, another operates, and the other - treats. It is almost impossible to hold a physician accountable for making an unconfirmed diagnosis, prescribing improper treatment or making a surgical error [13].

Respondents who shared their experiences as patients in other countries were asked to express their wishes and suggestions that they consider necessary for implementation in Ukraine. The vast majority of people called for: introduction of state insurance medicine; approval of the basic package of medical services accessible to all citizens; adoption of a number of laws to strengthen physicians' accountability for corruption, negligence and ethical retreat; first and foremost, change of the physician's attitude towards the patient as a client. As it turns out, no country other than Denmark has a unified system of medical records of patients, although electronic cards exist to identify patients in the system of access to medical services and insurance, but there is no complete paper or electronic record of patients anywhere. But now all the countries listed are moving in this direction.

So far, particular concern about the medical policy reform in Ukraine raises the issue of access of Ukrainian citizens living in the periphery to professional medical services for diagnosis and treatment. Most people in Europe and the US 
own cars. Therefore, even those who live in remote areas, because for them the car is not such a luxury as for us, can get to the nearest hospital. Other problems are added to the problem of lack of funds for medical special vehicles - the state of roads, the cost of fuel, components and cars themselves, the price of which in Ukraine exceeds prices in Europe and America. Not to mention the other issues the quality of hospital equipment that will be transferred to local budgets, difficulties with privatization and the creation of a professional and competitive market for health care workers, retraining and moral ethics are turning into a corrupt system of health care facilities, to business-physicians who can easily look for loopholes, for example, in further collaboration with pharmaceutical companies, despite clinical protocols.

Most importantly, there is a lack of positive experience with reforms implemented in many areas of public administration and effective public institutions that would ensure the consistency and irrevocability of these reforms. Moreover, it can be said without exaggeration that the success of the reforms depends on the society as a whole, and above all on the demand of the citizens of Ukraine for honest, transparent and professional medicine [12; 15].

Based on the analysis of the European experience in reforming public administration mechanisms of the health care system that can be used in Ukraine, the following conclusions can be drawn:

1. The experience of the US and European Union countries demonstrates the positive and negative aspects of forming organizational structures in the health care system. It seems that the key to implementing reform in Ukraine should be to emphasize the consistency of change and flexibility in finding optimal directions for the development of the national health care system. Ukraine should pay attention to the possibility of creating a full-fledged state compulsory health insurance fund instead of a mediation service.

2. It is established that a mixed model of organization of health care system is gradually being introduced in Ukraine, which will allow the state to officially guarantee every citizen the right to free medical care, to introduce additional mechanisms of financing medical care for those who need it, without increasing the cost of health care from the state budget [6, p. 351]. In this context, the German experience is useful in demonstrating the feasibility of setting up nongovernmental insurance funds (such as German health insurance funds) that will purchase medical services from public or private health care facilities, which will increase competition between them.

3. Ensuring the proper pace of health care development in Ukraine and bringing it closer to European standards requires finding new approaches to the functioning of the industry, financing the system through diversification of sources of funding as an alternative to budget financing.

Firstly, irrespective of the legal and organizational forms of health care used, the problem of the effective functioning of the health insurance system in most countries of the world is urgent and needs reform and improvement. 
Secondly, world experience confirms that the most vulnerable sections of the polulation in the first place need transformational changes in the medical sector to ensure effective social protection.

Thirdly, compulsory social health insurance needs to be implemented and developed to address social problems in society and to meet social standards.

Fourthly, voluntary health insurance is required to improve the quality of care.

Each state seeks to create the health care system that is the most ideologically, economically and mentally acceptable, so blind borrowing of ideas and copying of successful world systems for its development does not always have a positive effect. The goal of achieving the highest level of availability and quality of care assistance should be decisive for Ukraine. In doing so, it is imperative to take into account and balance public and private interests.

In this context, we consider the adoption of the Law of Ukraine "On compulsory social health insurance", which should clearly state the subjects of insurance, the mechanism of its financial security, sources of formation and directions of use of financial resources, as well as the list and categories of persons to be covered by this type of insurance.

It should be noted that the organization of financing health insurance means, as evidenced by the experience of other countries, fruitful cooperation in this system between the state providing compulsory health insurance and the private insurance sector providing voluntary health insurance services $[13, \mathrm{p}$. 70].

Conclusions. Based on the analysis of the effective practices of the functioning of health care systems in European countries, we can identify the principles that are important for the formation of the national system of public administration mechanisms of the health care system in Ukraine, including:

- the established process of interaction between the state, the private sector and the citizens themselves;

- balanced distribution of health care responsibilities between state and local authorities;

- organizing a health care system based on high competition and consumer orientation;

- accessibility of medical services, convenience in obtaining them through efficient use of available resources;

- creation and development of the health insurance system.

\section{References:}

1. Vovk, S. M. (2019), "Mechanisms of public administration of systemic changes in health care", abstract of doctor dissertation, mechanisms of public administration, Donetsk state university of management, Mariupol, Ukraine, $610 \mathrm{p}$.

2. Honcharova, O. (2017), "Medical reform - a panacea or ultimate destruction?", Pravona okhoronu zdorovia, retrieved from: http://khpg.org/index.php?id=1484060362.

3. Hryhorovych, V. R. (2010), "Improvement of management mechanisms of state support of the health care system in Ukraine", Derzhavne upravlinnia: udoskonalennia ta rozvytok, №2, retrieved from: http://nbuv.gov.ua/UJRN/Duur_2010_2_13. 
4. The Verkhovna Rada of Ukraine (2018), The Law of Ukraine "On the state financial guarantees of health care of the population", retrieved from: https://zakon.rada.gov.ua/laws/show/2168-19.

5. Karlash, V. V. (2020), "Mechanisms of state regulation of public health in Ukraine", abstract of doctor dissertation, mechanisms of public administration, National university of civil protection of Ukraine, Kharkiv, Ukraine, 307 p.

6. Knysh, S. V. (2019), "Administrative-legal relations in the field of health care in Ukraine”, abstract of doctor dissertation, administrative law and process; finance law; information law, Ternopil national economic university, Ternopil, Ukraine, $632 \mathrm{p}$.

7. Kostiuk, V. S. (2017), "Reforming health care in Ukraine in a European orientation", Naukovyi visnyk Mizhnarodnoho humanitarnoho universytetu. Seriia : Ekonomika i menedzhment, №24(2), retrieved from: http://nbuv.gov.ua/UJRN/Nvmgu_eim_2017_24\%282\%29_11.

8. The concept of the World Health Organization "Health 2020: Foundations of European Policy and Strategy for the 21st Century" (2020), retrieved from: http://www.euro.who.int/_data/assets/pdf_file/0017/215432/Health2020-Long-Rus.pdf.

9. Lytvynenko, M. V. (2015), "Principles of the national healthcare system in Ukraine", Teoriia ta praktyka derzhavnoho upravlinnia, №2, retrieved from: http://nbuv.gov.ua/UJRN/Tpdu_2015_2_33.

10.The official site of health care (2020), Newsletter "What was and will be", retrieved from: https://moz.gov.ua/uploads/2/13773-transition_book_health care.pdf.

11.Nonko, V. (2020), "Foreign experience in health insurance", FORYNShURER strakhovanye v Ukrayne. Novosty strakhovanyia, retrieved from: https://forinsurer.com/public/02/12/12/155.

12.Panchenko, I. (2017), "Patients about medicine. World experience", Tyzhden.ua, retrieved from: https://tyzhden.ua/Society/197814

13.Parkheta, L. V. (2018), "Health insurance and its role in financing the health care system in Ukraine", abstract of Ph.D. dissertation, money, finance and credit, State Higher Educational Institution "Kyiv Vadim Hetman National Economic University", Kyiv, Ukraine, 287 p.

14.Sokyrko, O. S. Kobzar, I. A. and Khanaliieva, I. S. (2018), "Development of health insurance: foreign experience and possibilities of its use in Ukraine”, Ekonomika i suspilstvo, №19, retrieved from: http://economyandsociety.in.ua/journal/19_ukr/171.pdf.

15.Tkachova, N. M. (2018), "Areas of reforming public health policy", Investytsii: praktyka ta dosvid, №8, retrieved from: http://www.investplan.com.ua/pdf/8_2018/19.pdf.

16.Turchak, D. V. (2019), "Mechanisms of public-private partnership in the field of health", abstract of Ph.D. dissertation, mechanisms of public administration, Institute of training of the state employment service of Ukraine, Kyiv, Ukraine, 315 p.

17.Iaremchuk, O. V. (2018), "Best foreign practice in family medicine: experience for Ukraine", Derzhavne upravlinnia: udoskonalennia ta rozvytok, № 11, retrieved from: http://www.dy.nayka.com.ua/pdf/11_2018/101.pdf.

18. Health Insurance in Ukraine: Do You Really Need How to Choose a Package and Prices (2020), retrieved

from:

https://zik.ua/news/2018/08/24/medychna_strahovka_v_ukraini_chy_diysno_potribna_yak_obraty_pa ket_i_tsiny_1392845.

Received: January 20, 2020 